TOURNAL OF SOciaL

\title{
РЕЦЕНЗИИ
}

\author{
Анна Казакова
}

\section{ПРОДОВОЛЬСТВЕННАЯ БЛАГОТВОРИТЕЛЬНОСТЬ КАК СТИМУЛЯЦИЯ ГОЛОДА}

\section{Lambie-Mumford H., Silvasti T. (eds.) (2020) \\ The Rise of Food Charity in Europe. Bristol: Policy Press. 252 p. ISBN 978-1-4473-4000-3}

DOI: $10.17323 / 727-0634-2020-18-4-765-774$

Со времен Второй Мировой войны голод включен в число глобальных проблем человечества (Островская 2014). Он входит в десятку важнейших мировых угроз, которые ежегодно обсуждаются на Мировом экономическом форуме (World Economic Forum 2016). Международные меры по борьбе курируются ФАО (Food and Agriculture Organization), специализированным подразделением ООН. Ликвидация голода и недоедания- одна из 17 целей устойчивого развития, заявленных странами-членами ООН на 2015-2030 гг. в Декларации «Мир, которого мы хотим» (Юрлова 2016). И вместе с тем, как видно из индикаторов открытой статистики ФАО (Food and Agriculture Organization 2020), в международном учете значительно большее внимание уделяется проблемам биоразнообразия планеты, производства сельхозпродукции, определения ее стандартов и поддержания ее качества, чем проблемам распределения и доступности продовольствия различным социальным группам.

Экономисты скептически высказываются о достоверности оценок масштабов голода, связывая их пестроту с нечеткостью принятых для

Анна Юрьевна Казакова-к.с.н., доцент, кафедра философии и культурологии, Калужский государственный университет имени К. Э. Циолковского, Калуга, Россия. Электронная почта: kazakova.a.u@yandex.ru 
статистического учета показателей из-за разночтений в самой его идентификации (Карманов, Кузин 2014). Глубокого теоретического осмысления голода как социального явления не появлялось после основополагающих работ Питирима Сорокина 1920-1940-х г.г. (Сорокин 1921; 1922; 2003; 2012). В современной научной литературе социальная детерминированность голода монополизирована историей, где голод стал объектом не только научного изучения, но и политическим инструментом (см.: напр., Грозин 2017). Последнее монографическое исследование голода в русскоязычной социологической литературе-диссертация на материале Эфиопии (Сарбесса 1994). Вне контекста современных стран третьего мира либо исторических последствий катастрофических событий голод и вызванные им потери и патологии, формы помощи голодающим, меры борьбы с голодом-малопривлекательные для российских авторов и малоизвестные русскоязычной читающей публике темы.

Как отмечает в предисловии вице-директор Школы социальной работы Университета Британской Колумбии профессор Грэм Ричес, включение данной книги в актуальную научную повестку- факт одновременно тревожный и обнадеживающий. Тревогу вызывает общественный контекст появления книги: голод перестал быть специфическим бедствием стран третьего мира, далеким от интересов Европы, где концентрируется значительная доля мирового среднего класса. Пионеру исследований продовольственной безопасности и активному пропагандисту «права на еду» (Riches 1986; 2018) должны быть особенно близки идеологические лейтмотивы рецензируемого издания: критика неолиберализма, корпоративизма, жесткой экономии государств на социальной защите, международной экспансии США в форме продвижения своих продовольственных банков в ущерб системам социального обеспечения других государств. Иронизируя над привычкой политиков маскировать голод эвфемизмами типа «угроза продовольственной безопасности», Ричес считает отрадным сам факт появления книги, где вещи названы своими именами и исследованы объективно. Широкий сравнительный фон социальной политики семи европейских государств обеспечивает значительный вклад не только в специальную область знаний, но и в растущую международную дискуссию о правах человека и гражданском обществе.

Книга «Развитие продовольственной благотворительности в Европе» появилась благодаря поддержке Шеффилдского университета (Великобритания), факультета общественных наук и научно-исследовательского Института продовольствия, который занимается проблемами устойчивости общественного развития в аспекте продовольственной безопасности. Помимо финансирования, университет исполнил роль коммуникационной площадки для географически разбросанного авторского коллектива. Кроме Великобритании, он представлен Германией, Испанией, Италией, Нидерландами, Словенией, Финляндией. Такой географический разброс интересен для компаративного анализа. Авторы представляют страны с разными уровнями 
экономического развития, типами государственной социальной политики, традициями благотворительности, что делает эмпирический материал релевантным главной цели- выявить основные факторы, уже несколько десятилетий стимулирующие подъем продуктовой благотворительности в общеевропейских масштабах. Концентрация внимания на проблеме вклада благотворительности в благосостояние и соблюдение социальных прав в условиях, когда государство сужает свою ответственность, сближает книгу с монографическим жанром, хотя редакторы-Ханна Лэмби-Мамфорд и Тиина Сильвасти- определяют жанр как сборник статей.

Заслугой редакторов является легкость восприятия и удобство работы с книгой благодаря навигационным и справочным элементам (предметноименной указатель, перечень иллюстративного материала, авторские справки), структурной стройности за счет жесткой параллельной композиции основной части. Главными аспектами темы стали: «природа и масштабы продовольственной благотворительности; соотношение перемен в социальном обеспечении граждан и роста продовольственной благотворительности, а также благотворительности в целом; роль помощи продуктами в формировании продовольственной благотворительности; понимание социальной справедливости там, где меняется государственное социальное обеспечение и растет продовольственная благотворительность» (Р. 220). Эта тематика развертывается в главах основной части.

Практически единственный, но досадный недостаток работы-отсутствие в статьях (за исключением словенских авторов) методических разделов, которые позволили бы составить комплексное представление об исследовательской программе и ее воплощении. Это связано с тем, что вся книга строится преимущественно на вторичных источниках: результатах сторонних исследований, официальных документах, агрегированных статистических данных. Их верификация, оценка релевантности использованных в цитируемых источниках методов авторами (за исключением финских) не приводится, а соответственно, сопоставимость результатов остается под вопросом, и мы не получаем апробированной методики оценки эффективности обсуждаемых благотворительных практик, равно как и четко выделенных критериев этой эффективности. Авторы глав выделяют похожие подразделы, по-видимому, следуя редакторской повестке, но реализованный проект едва ли можно назвать собственно компаративным исследованием, одновременно проведенным в разных странах по единой программе, методике, с последующей обработкой всего комплекса собранных данных.

Каждый автор предпринимает традиционный обзор состояния научного изучения тех или иных аспектов темы. Это научная литература о формах и социальных причинах голода; историография наиболее тяжелых случаев массового голода различного генезиса; теоретико-методологические подходы к определению нищеты и крайней бедности, место голода в системе их характеристик; социальные и медико-демографические последствия пищевой 
депривации; субъекты и формы оказания продовольственной помощи, ее виды, бенефициары и механизмы; становление фудшеринга и пищевых банков в национальных государствах в контексте специфичной для конкретного исторического момента политической ситуации; дискуссии в общественно-политических СМИ вокруг социального и продовольственного обеспечения граждан, экологической ситуации, пищевой ценности и качества продуктов питания, состояния АПК и продуктовых потерь в цепи доставки пищи от производителя к домохозяйству. Благодаря этому возникает обширная и, вероятно, исчерпывающая библиография современных изысканий в сфере продовольственной безопасности. Поскольку авторы опираются прежде всего на отечественный опыт, привлекая данные национальной статистики и наиболее крупные, известные зарубежные исследовательские проекты, мы получаем возможность определить персоналии и работы, которые сегодня рассматриваются как эталонные, хрестоматийные, обязательные для студентов и научных работников целого ряда специальностей в области экономики, сельского хозяйства, политологии, социологии и социальной работы. Часто члены авторского коллектива ссылаются на многочисленные предыдущие публикации редакторов и рецензента, профессора Ричеса.

Методологическую основу книги образуют депривационный подход Питера Таунсенда, концепция новой бедности как следствия глобализации и цифровизации мира Зигмунта Баумана, концепция прекаризации Пьера Бурдье, анализ Лоиком Ваканом криминализации бедности на основе стигматизирующего неолиберального дискурса, концепция моральной паники как механизма конструирования девиантности в версии Рагнара Лундстрема. Важной опорной категорией выступает социальная эксклюзия, которая трактуется прежде всего как правовая депривация, когда отдельные социальные группы по разным причинам выпадают за пределы нормативного пространства защищенности законом, что в чрезвычайных обстоятельствах, в условиях социальной катастрофы лишает их возможности выжить. Моделируя преодоление эксклюзии, авторы используют разные концепции социальной справедливости или социальной солидарности, в частности, идею глобального правового сообщества Хауке Брункхорста.

Универсальный для всех авторов элемент научного аппарата- право на еду. Это понятие, которое возводят к Франклину Рузвельту (Прохазка 2011), закрепленное в международном праве, представляется им слишком очевидным для самостоятельных интерпретаций. Вместе с тем оно звучит непривычно для русскоязычного читателя, далекого от правоведения или экономики сельского хозяйства (Митин, Воронин 2017). Редакторы приводят определение права на еду, данное Жаном Зиглером, исследователем стран третьего мира, вице-президентом консультативного совета $\mathrm{OOH}$ по правам человека. Это право «иметь регулярный, постоянный и неограниченный доступ, либо непосредственно, либо посредством финансовых закупок, к количественно и качественно адекватному и достаточному пи- 
танию, соответствующему культурным традициям народа, к которому принадлежит потребитель, и обеспечивающему физическую и умственную, индивидуальную и коллективную, полноценную и достойную жизнь, свободную от страха» (Р. 8). Зиглер убежден в исключительно рукотворном характере, а значит, и в принципиальной преодолимости голода как социального явления. По его мнению, голод возникает вследствие спекуляций на мировом продовольственном рынке, в узких корпоративных интересах экономических и политических элит. Авторский коллектив солидарен с этой идеей, дополняя, что и продовольственная благотворительность парадоксальным образом не снижает, а усугубляет хронический голод обездоленных в европейских государствах. По мере того, как благотворительные организации затыкают дыры в государственном обеспечении, по мере роста числа продовольственных банков, растет и выброс корпоративными субъектами в экономику благотворительности пищевых излишков и пищевых отходов, пока политический дискурс восхваляет благотворительность, филантропию и волонтерство, а государство сокращает расходы на социальную защиту населения, предпочитая поддерживать благотворителей, а не тех, кто вынужден прибегать к их помощи.

Кроме того, сама благотворительная деятельность пронизана неолиберальными принципами и практиками: например, авторы из Германии и Словении указывают, что претендент на получение продуктовой помощи должен, чтобы подтвердить реальную нужду, проходить тестирование. В Нидерландах и Великобритании установлена сложная система критериев, которым нуждающийся должен соответствовать. В итоге на фоне неравенства в доступе к продовольствию возникает производное неравенство-в доступе к получению продовольственных пособий. Их получатель стигматизируется и испытывает чувство стыда, а государство между тем ведет социальное обеспечение все более избирательно, осознанно сужая круг адресатов (в Нидерландах, Германии, Великобритании, Словении и Финляндии), или форм помощи (Испания, Италия), или ее размеры (в Великобритании, Германии, Словении и Финляндии). При этом авторы вовсе не отрицают, что первоначально благотворители могут быть движимы состраданием и чувством ответственности за обездоленных сограждан. Но, хотя ни один из них не упоминает Питирима Сорокина в числе идейных вдохновителей реализованного проекта, заметно, что выявленные ими тенденции подтверждают сорокинский «закон обратного иллюзионизма» (результаты революции противоречат лозунгам, которые ее вдохновляли, а больнее всего негативные эффекты ударяют по тем самым обездоленным, от лица которых говорит революция и чьи интересы она намерена защищать).

Интересно, что и постулат рукотворности голода косвенно подтверждается в выводах, к которым приходят даже наименее радикальные из постсоветских историков. События 1930-х гг. выводят из предшествующей политики продвижения групповых (классовых или партийных), а не общена- 
циональных интересов (Помогалова 2013); из практик конфискации собственности и насильственного внедрения новых форм хозяйствования (Грозин 2017); из слабости макроэкономических регуляторов при смене технологического уклада в сочетании с «усиленным применением политических инструментов, что создает условия для деформации системы общественных ценностей» (Макаренко 2014: 180). Исходя из результатов исследования Майкла Эллмана, большинство примеров массового голода в отечественной истории (и, как следует из рецензируемой работы, за рубежом) можно отнести к типу предотвратимого спада в обеспечении продовольствием. Голод 1946-1947 гг. «...был обусловлен засухой, вызвавшей неурожай и ухудшившей продовольственное снабжение, однако, если бы приоритеты правительства были иными, голода можно было бы избежать (или он не был бы столь значительным), несмотря на засуху» (Эллман 2005: 320). Но потенциально массовый голод может быть еще и репрессивной практикой: «Власть устанавливает гастрономический режим, который является инструментом эффективного управления. Голод и идеология всегда давали возможность управлять насильственным способом. Сытость, изобилие и связанная с ними идеология удовольствия являются способом мягкого дисциплинирования сегодня» (Сохань 2014: 79). Эта пронизанная духом работ Мишеля Фуко идея функционирования голода, а еще больше- дозированного и негарантированного предоставления доступа к пище как социокультурного регулятора, как средства социальной дрессуры перекликается с обильными примерами криминализации бедности и стигматизации получателей продуктовых пособий, навязывания им заведомо сниженного потребительского стандарта и образа жизни, лимитированного практиками, нацеленными на удовлетворение только пищевых потребностей, которые приводятся в «Росте благотворительности в Европе».

Подводя итоги, редакторы подчеркивают, что на примере продуктовой благотворительности легче разглядеть общие сдвиги в реагировании социальной политики европейских государств на бедность. Резюме состоит в необходимости радикальной смены ее приоритетов, прежде всего в отказе от продвижения продуктовой благотворительности в ущерб защите социальных прав граждан и борьбе с неравенством по доходам. Важнейшую роль в этих процессах, по мнению авторов, должно играть давление гражданского общества на преступные правительства, прямой обязанностью которых является создание законодательной рамки и программ национального развития, нацеленных на искоренение нищеты и обеспечение всеобщей продовольственной безопасности.

Перспективными для России результатами можно считать следующие. «Ландшафты» продуктовой благотворительности неоднородны в различных странах, что затрудняет их количественное сопоставление, а критерии для оценки ее эффективности как средства сокращения голода и как средства смягчения социальной напряженности, равно как и для оценки глубины 
и последствий самого голода для разных социальных групп, по-прежнему не выработаны. Поскольку социальная политика если не прямо подчиняется экономике, то сильно корректируется экономической ситуацией, всплески продовольственной благотворительности повсеместно наблюдаются в условиях экономического кризиса и падения государственной поддержки. Независимо от исторической роли третьего сектора в различных режимах социальной защиты, на неолиберальной волне роль благотворительности резко возросла и в тех странах, где основным источником социальной поддержки является государство, и в тех, где основным ее источником является семья. Продовольственная помощь в условиях чрезвычайных ситуаций показывает, насколько влияют на социальную политику другие сферы политики государства- аграрной или экологической- и как передача излишков на благотворительные цели делает использование продуктовых пакетов более широким и привычным, то есть насколько важна превентивная деятельность государств по предотвращению техногенных аварий и природных катастроф. Получатели продовольственной помощи (в виде продуктовых пакетов, или распродаж по «социальным»- сниженнымценам, или в виде талонов для членов продовольственных кооперативов, иных потребительских ячеек типа клиентов общественных кухонь, передвижных пунктов раздачи бесплатной еды и пр.) не являются самоцелью для субъектов продуктовой благотворительности. Они включены в цикл «экологичной»- безотходной- экономики, ориентированной на ремонт, переработку и повторное использование, воспроизводство, сокращение издержек, только потому, что именно они изначально являются основными потребителями пищевых излишков и пищевых отходов.

Развернутая в книге концепция убедительна и эвристична, обоснована теоретически и способна не только предостеречь от внедрения в сферах социальной защиты и социальной работы уже дискредитированных на Западе практик, но и дать импульс к переосмыслению природы и источников самых различных видов депривации. Если распространение продуктовой благотворительности знаменует крах системы социальной защиты населения, если рукотворный голод является не только случайным побочным эффектом, но и осознанной целью отдельных групп, заинтересованных в его искусственном стимулировании, то необходим пересмотр целого ряда привычных представлений: о нищете, бедности, жилищной проблеме и проблемах рынка труда, об «андерклассе» и источниках его пополнения, об адекватности социальной политики и ее главной ценности-социальной справедливости.

\section{Список источников}

Грозин А.В. (2017) Голод 1932-1933 гг. в Казахстане: Феномен мифологизации истории как составная часть глобальной информационной войны. Постсоветский материк, (1): 107-125. 
Карманов М. В., Кузин С.И. (2014) Голод как актуальный объект прикладных статистических исследований. Вестник Российского экономического университета им. Г.В. Плеханова, (4): 12-21.

Макаренко И.П. (2014) Эволюционные предпосылки возникновения голода в периоды социально-экономических кризисов. Демографія та соціальна економіка, (1): 180-191.

Митин А.Н., Воронин Б. А. (2017) Экономика продовольствия. Аграрный вестник Урала, (1): 18.

Островская Е.Я. (2014) Роль ФАО в решении мировой продовольственной проблемы. Сельское, лесное и водное хозяйство. Доступно по ссылке: http://agro.snauka. $\mathrm{ru} / 2014 / 01 / 1290$ (дата обращения: 15 июля 2020).

Помогалова О.И. (2013) Помощь иностранных благотворительных организаций голодающим Саратовского Поволжья (1921-1923 гг.). Автореф. дис. ... канд. ист. наук. Саратов: СГУ.

Прохазка А.А. (2011) Эволюция права на надлежащее питание в международно-правовой системе. Проблемы законности, 116. Доступно по ссылке: https:/cyberleninka.ru/ article/n/evolyutsiya-prava-na-nadlezhaschee-pitanie-v-mezhdunarodno-pravovoy-sisteme (дата обращения: 15 июля 2020).

Сарбесса Т. Л. (1994) Голод как сочиальное явление (на примере Эфиопии). Автореферат дис. ... кандидата социологических наук: 22.00.04. Санкт-Петербург. 17 с.: ил.

Сорокин П. А. (1921) Голод и убеждения (идеология) человека. Артельное дело, (6): 11-16.

Сорокин П.А. (1922) Влияние голода на социально-экономическую организацию общества. Экономист, (2): 23-53.

Сорокин П.А. (2003) Голод как фактор. Влияние голода на поведение людей, сочиильную организацию и общественную жизнь. М.: Академия.

Сорокин П.А. (2012) Человек и общество в условиях бедствий: влияние войнь, револючии, голода, эпидемии на интеллект и поведение человека, социальную организацию и культурную жизнь. СПб.: Мир.

Сохань И.В. (2014) Гастрономические практики власти- прошлое и настоящее. Человек. Культура. Образование, (2): 79-90.

Эллман М. (2005) Голод в СССР в 1947 г. в свете проблемы «доступа к продовольствию». Экономическая история, (ежегодник):320-363.

Юрлова Е.С. (2016) Уязвимые слои населения и бедность. Азия и Африка сегодня, (12): $38-42$.

Food and Agriculture Organization (2020) Food security statistics. Доступно по ссылке: http://www.fao.org/economic/ess/ess-fs/en/ (assessed 15 July 2020).

Riches G. (1986) Food Banks and the Welfare Crisis. Ottawa: Lorimer.

Riches G. (2018) Food Bank Nations, Corporate Charity and the Right to Food. London: Routledge.

World Economic Forum (2016) What are the 10 Biggest Global Challenges? Доступно по ссылке: https://www.weforum.org/agenda/2016/01/what-are-the-10-biggest-globalchallenges/ (assessed 15 July 2020). 
Anna Kazakova

FOOD CHARITY AS THE STIMULATION OF HUNGER

Lambie-Mumford H., Silvasti T. (eds.) (2020) The Rise of Food Charity in Europe.
Bristol: Policy Press. 252 p. ISBN 978-1-4473-4000-3

DOI: 10.17323/727-0634-2020-18-4-765-774

\section{References}

Ellman M. (2005) Golod v SSSR v 1947 g. v svete problemy 'dostupa k prodovol'stviyu' [Famine in the USSR in 1947 in the Light of the Problem of 'Access to Food']. Ekonomicheskaya istoriya, [Economic history], (yearbook): 320-363.

Food and Agriculture Organization (2020) Food security statistics. Available at: http:// www.fao.org/economic/ess/ess-fs/en/ (assessed 15 July 2020).

Grozin A. V. (2017) Golod 1932-1933 gg. v Kazahstane: Fenomen mifologizacii istorii kak sostavnaya chast' global'noj informacionnoj vojny [Famine of 1932-1933 in Kazakhstan: The Phenomenon of Mythologization of History as an Integral Part of the Global Information War]. Postsovetskij materik [Post-Soviet Continent], (1): 107-125.

Karmanov M.V., Kuzin S.I. (2014). Golod kak aktual'nyj ob"ekt prikladnyh statisticheskih issledovanij [Hunger as an actual object of applied statistical research]. Vestnik Rossijskogo ekonomicheskogo universiteta im. G.V. Plekhanova [Bulletin of The Plekhanov Russian University of Economics], (4): 12-21.

Makarenko I.P (2014) Evolyucionnye predposylki vozniknoveniya goloda v periody social'no-ekonomicheskih krizisov [Evolutionary Prerequisites for the Emergence of Famine in Periods of Socio-Economic Crises]. Demografiya ta social'na ekonomika [Demographics and Social Economy], (1): 180-191.

Mitin A. N., Voronin B.A. (2017) Ekonomika prodovol'stviya [The Economy of Food]. Agrarnyj vestnik Urala [Agrarian Bulletin of the Urals], (1): 18.

Ostrovskaya E. Ya. (2014) Rol' FAO v reshenii mirovoj prodovol'stvennoj problemy [The Role of FAO in Solving the World Food Problem]. Sel'skoe, lesnoe i vodnoe hozyajstvo [Agriculture, Forestry and Water Management]. Available at: http://agro.snauka.ru/2014/01/1290 (assessed 15 July 2020).

Pomogalova O.I. (2013) Pomoshch' inostrannyh blagotvoritel'nyh organizacij golodayushchim Saratovskogo Povolzh'ya (1921-1923 gg.) [Assistance of Foreign Charitable Organizations to the Starving People of the Saratov Volga Region (1921-1923)], avtoref. dis. ... kand. ist. Nauk [author's abstract. ... candidate of historical Sciences]. Saratov: Saratov state University.

Anna Kazakova - Cand. Sci. (Sociol.), associate Professor, Department of philosophy and cultural studies, Kaluga state University named after K. E. Tsiolkovsky, Kaluga, Russia. Email: kazakova.a.u@yandex.ru 
Prohazka A. A. (2011) Evolyuciya prava na nadlezhashchee pitanie v mezhdunarodno-pravovoj sisteme [Evolution of the Right to Adequate Food in the International Legal System]. Problemy zakonnosti [Problems of Legality], 116. Available at: https://cyberleninka.ru/ article/n/evolyutsiya-prava-na-nadlezhaschee-pitanie-v-mezhdunarodno-pravovoy-sisteme (assessed 15 July 2020).

Riches G. (1986) Food Banks and the Welfare Crisis. Ottawa: Lorimer.

Riches G. (2018) Food Bank Nations, Corporate Charity and the Right to Food. London: Routledge.

Sarbessa T.L. (1994) Golod kak social'noe yavlenie (na primere Efiopii [Hunger as a Social Phenomenon (On ehe Example of Ethiopia)]. Abstract of dis. ... candidate of sociological Sciences: 22.00.04]. Saint Petersburg.17 p.: il.

Sohan' I.V. (2014) Gastronomicheskie praktiki vlasti- proshloe i nastoyashchee [Gastronomic Practices of Power-past and Present]. Chelovek. Kul'tura. Obrazovanie [Person. Culture. Education], (2): 79-90.

Sorokin P. A. (1921) Golod i ubezhdeniya (ideologiya) cheloveka [Hunger and Beliefs (Ideology) of a Person]. Artel'noe delo [Artel business], (6): 11-16.

Sorokin P.A. (1922) Vliyanie goloda na social'no-ekonomicheskuyu organizaciyu obshchestva [The Impact of Hunger on the Socio-Economic Organization of Society]. Ekonomist [Economist], (2):23-53.

Sorokin P. A. (2003) Golod kak faktor. Vliyanie goloda na povedenie lyudej, social'nuyu organizaciyu i obshchestvennuyu zhizn' [Hunger as a Factor. The Impact of Hunger on Human Behavior, Social Organization and Social Life]. Moscow: Akademiya.

Sorokin P. A. (2012) Chelovek i obshchestvo v usloviyah bedstvij: Vliyanie vojny, revolyucii, goloda, epidemii na intellekt i povedenie cheloveka, social'nuyu organizaciyu i kul'turnuyu zhizn' [Man and Society in the Face of Disasters: The Impact of War, Revolution, Famine, and Epidemic on Human Intelligence and Behavior, Social Organization, and Cultural Life]. St. Petersburg: Mir.

World Economic Forum (2016) What are the 10 Biggest Global Challenges? Available at: https://www.weforum.org/agenda/2016/01/what-are-the-10-biggest-global-challenges/ (assessed 15 July 2020).

Yurlova E. S. (2016) Uyazvimye sloi naseleniya i bednost' [Vulnerable Populations and Poverty]. Aziya i Afrika segodnya [Asia and Africa Today], (12):38-42. 